\title{
Usefulness of the endoscopic surgical skill qualification system in laparoscopic colorectal surgery: short-term outcomes: a single-center and retrospective analysis
}

\author{
Shota Aoyama* (D), Yuji Inoue, Takeshi Ohki, Michio Itabashi and Masakazu Yamamoto
}

\begin{abstract}
Background: The use of laparoscopic surgery has become widespread, and many surgeons are striving to acquire the necessary techniques for it. The Endoscopic Surgical Skill Qualification System (ESSQS), established by the Japan Society for Endoscopic Surgery, serves to maintain and improve the quality of laparoscopic surgery in Japan. In this study, we aimed to determine whether ESSQS certification is useful in maintaining and improving the quality of surgical techniques and in standardization of laparoscopic surgery in Japan.

Methods: This retrospective study used data from the Institute for Integrated Medical Sciences, Tokyo Women's Medical University, Japan. From January 2016 to October 2017, 241 patients with colorectal cancer underwent laparoscopic surgery. Of them, 220 patients were selected and divided into two groups on the basis of surgery performed by an ESSQS-qualified surgeon (QS group) $(n=170)$ and a non-ESSQS-QS (NQS) $(n=50)$. We compared the short-term results in the two groups and examined those before and after propensity score matching (PSM).

Results: Mean operation time was longer in the NQS group than in the QS group. Furthermore, mean blood loss was significantly less in the QS group. These were similar before and after PSM. The rate of conversion to open surgery was significantly higher in the NQS group before PSM. However, the rate of postoperative complications was not different between the two groups.

Conclusions: A laparoscopic procedure performed by ESSQS-QS often leads to good short-term outcomes. Thus, the ESSQS system works and is potentially useful in maintaining and improving the quality of surgical techniques and in standardization of laparoscopic surgery in Japan.
\end{abstract}

Keywords: Endoscopic surgical skill qualification system, Qualified surgeon, Laparoscopic surgery, Colorectal cancer, Short-term outcomes, Propensity score matching

\section{Background}

The use of laparoscopic surgery has become widespread because this technique can be easily adapted to various organs and disease treatments. In colorectal surgery, using a laparoscopic rather than open approach generally leads to faster recovery, reduced duration of postoperative ileus, lower wound infection rates, shorter hospital stay, reduced postoperative pain, and earlier tolerance of a regular diet $[1,2]$. However, laparoscopic

\footnotetext{
* Correspondence: aoyama.shota@twmu.ac.jp

Department of Gastroenterological Surgery, Tokyo Women's Medical University, 8-1, Kawada-cho, Shinjuku-ku, Tokyo 162-8666, Japan
}

surgical techniques are difficult to master, and a laparoscopic approach is associated with an increased operation time compared with an open approach $[1,2]$. In an attempt to standardize laparoscopic surgery in Japan, the Endoscopic Surgical Skill Qualification System (ESSQS), established by the Japan Society for Endoscopic Surgery (JSES), serves to maintain and improve the quality of surgical technique and to standardize laparoscopic surgery [3-5]. Applicants who want to have the privileges of endoscopic surgeons are required to submit certain documents, including a letter certifying 2 years of uninterrupted endoscopic surgical practice after

(c) The Author(s). 2019 Open Access This article is distributed under the terms of the Creative Commons Attribution 4.0 International License (http://creativecommons.org/licenses/by/4.0/), which permits unrestricted use, distribution, and reproduction in any medium, provided you give appropriate credit to the original author(s) and the source, provide a link to the Creative Commons license, and indicate if changes were made. The Creative Commons Public Domain Dedication waiver (http://creativecommons.org/publicdomain/zero/1.0/) applies to the data made available in this article, unless otherwise stated. 
completion of all formal training, a certificate of membership of the JSES, and the special board of the Japan Society of Surgery, certificates of attendance of meetings and seminars held under the auspices of the JSES, a bibliography showing papers presented at the meetings or papers published in the authorized journals of the JSES, in addition to a list of endoscopic surgeries the applicant has performed by himself or herself over the last 3 years, together with an unedited Video, showing the surgery carried out by his or her own effort, and suturing and knotting techniques the applicant performed by him or herself. They are all screened and evaluated very seriously by committee members elected from individual Committees in order to make a final decision. For video evaluation, two judges, elected from the individual society, review the video using a score sheet, with detailed checking points and mark allocation. Checking points are divided into 2 parts consisting of: "common criteria" for basic endoscopic techniques commonly used for all procedures, and "organ-specific criteria" for special endoscopic surgical techniques for individual organs. The allotted marks for each criterion are 60 and 40 points respectively. The evaluation is focused on surgical techniques and camera work and a total score of 70 points is designated as the pass mark. The number of certificate holders certified in the field of Gastroenterological Surgery during the period from 2003 to 2012 is around 1000, with an average success rate of around $50 \%$. The main reason for the low success rate is attributable to their mainly immature techniques including careless handling of organs with inadequate instruments, or an inadequate operative field and a lack of communication among operators. [4]

This certification system is original and unmatched worldwide, and it is expected to be extremely useful for improving surgical outcomes and reducing complications. However, studies proving the usefulness of ESSQS have not been published since 2004. In this study, we aimed to determine whether ESSQS is useful in maintaining and improving the quality of surgical techniques and in the standardization of laparoscopic surgery in Japan.

\section{Materials and methods}

We focused on laparoscopic colorectal surgery and limited our study only to patients who underwent colorectal cancer surgery and in whom the pathology was diagnosed using postoperative pathological specimens, excluding those with autoimmune diseases, benign diseases, and malignant lymphomas. In this retrospective case-controlled study, we used data from the Institute for Integrated Medical Sciences, Tokyo Women's Medical University, Japan.

From January 2016 to October 2017, 241 patients with colorectal cancer underwent laparoscopic surgery. Excluding patients with simultaneous resection of the other organs $(n=15)$, two or more colon resections in the same operation $(n=2)$, and robot-assisted surgery $(n=4)$, the remaining 220 patients were included. Patients were divided into two groups on the basis of surgery performed by an ESSQS-qualified surgeon (QS group) $(n=170)$ and a nonESSQS-QS (NQS) $(n=50)$. The surgical team in the QS group generally included an ESSQS-qualified lead surgeon, a laparoscopic surgical assistant, or a camera operator. In the QS group, 118 surgeries were performed with QS; of them, 52 surgeries were performed with NQS in presence of a laparoscopic surgical assistant or camera operator with QS (Fig. 1). In the NQS group, ESSQS-QS did not participate in any of the surgeries.

At our facility, we conduct group medical examination based on the organ, and there are 10 surgeons in the colorectal group. They all possess more than 5 years of surgical experience, and three of them are ESSQS qualified. In QS surgeon group, One surgeon with more than 15 years of experience, one with more than 20 years and one with more than 25 years. On the other hand, in another group, five surgeons have experience as a surgeon for more than 10 years, in addition, one more than 20 years and one had more than 25 years' experience. Generally, laparoscopic procedures included three physicians from our team: lead surgeon, assistant, and camera operator. All surgical procedures and roles of participating physicians were decided at preoperative team staff conferences, and almost every surgery proceeded as planned. The extent of lymph node dissection was decided by the lead surgeon before the surgery. However, our result of this time derived the extent of dissection from the pathological result after the operation.

We retrospectively analyzed the following short-term outcomes after laparoscopic surgeries: operation time (min), blood loss (ml), conversion to open surgery, lymph node dissection level, number of lymph nodes harvested, postoperative complications, and postoperative stay in the hospital (day). Conversion to open surgery was intraoperatively judged by the lead surgeon. Patient management during the perioperative period was similar in all cases except for minor variations in perioperative antibiotics because of group medical examination. Postoperative complications were evaluated according to the Clavien-Dindo classification [6]. All enrolled patients gave their informed consent. This study was approved by the institutional review board of the Tokyo Women's Medical University Hospital.

\section{Statistical analysis}

We used JMP Pro 11 software (SAS Institute, Cary, NC, USA) for all statistical analyses. All quantitative variables were reported as means. Continuous variables for the two groups were checked for normality of distribution using one-sample Kolmogorov-Smirnov test and 
Laparoscopic colorectal surgery for colorectal carcinoma: 241

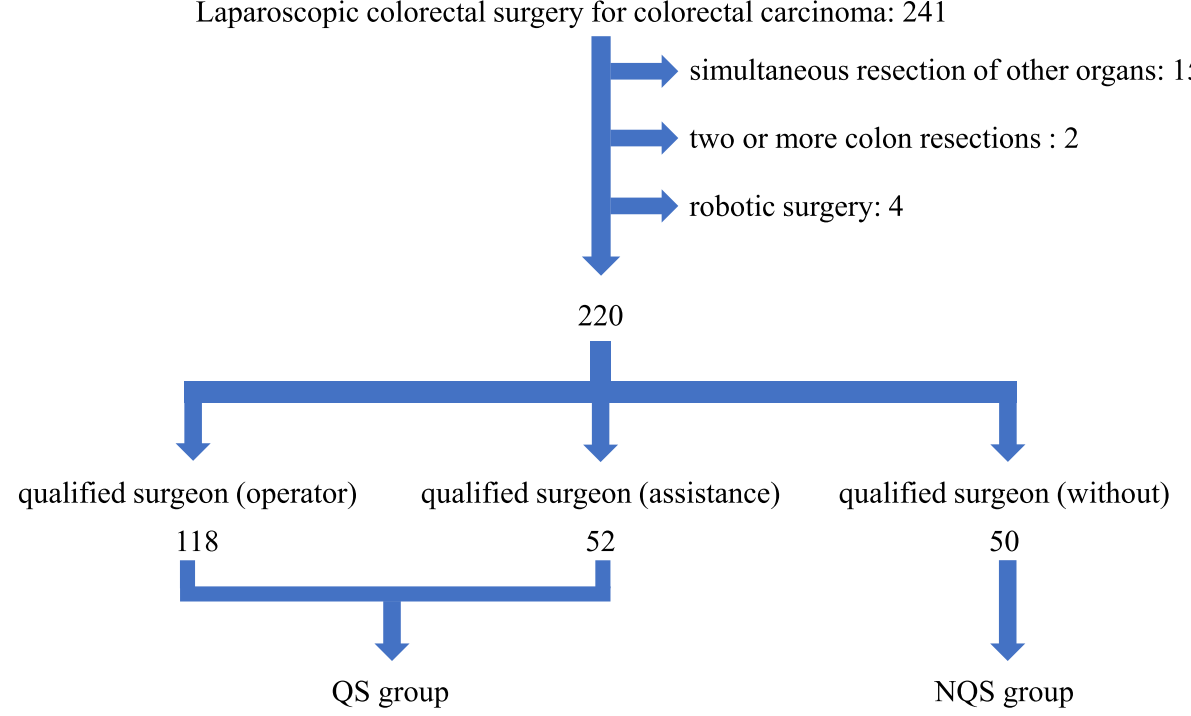

Fig. 1 Two hundred forty-one patients with colorectal cancer underwent laparoscopic surgery. We excluded patients with the following: simultaneous resection of the other organs $(n=15)$, two or more colon resections $(n=2)$, and robot-assisted surgery $(n=4)$. We divided remaining patients into two groups: QS group $(n=170)$ and NQS group $(n=50)$. Surgical team in QS group included a lead surgeon, assistant, or camera operator. In the QS group, 118 surgeries were performed with QS, and there was either an assistant or camera operator in 52 surgeries. For the NQS group, no ESSQS-qualified surgeons participated

compared using analysis of variance (Student's $t$-test or Mann-Whitney $U$ test). Binomial and categorical data were evaluated by cross-linked tables using Pearson's $\mathrm{v}^{2}$ or two-tailed Fisher's exact tests. Univariate analysis (non-parametric Wilcoxon two-sample test for continuous variables and $\mathrm{X}^{2}$ test for categorical variables) was performed for both groups. To identify independent risk factors for short-term outcomes using multivariate analysis, all significant variables evaluated on univariate analysis were integrated into multiple logistic regression and multiple regression analyses. $P<0.05$ was considered significant (Table 1 ).

\section{Propensity score matching}

We used PSM to minimize the differences in baseline characteristics between the QS and NQS groups. The following variables were included to establish the model: age, gender, body mass index (BMI), the American Society of Anesthesiologists (ASA) score, history of abdominal surgery, stage, anastomosis, tumor size, tumor location, operative procedure. After PS generation, patients in the QS and NQS groups underwent 1:1 nearest available matching of the logit of the propensity score with a caliper width of 0.20 of the standard deviation of the score. Patients who did not meet the matching criteria were excluded.

\section{Results}

Patient demographic characteristics

We were able to assign 220 included patients to either of the two groups (Fig. 1). Table 2 compares the characteristics of the patients in two groups. There was no difference between the QS and NQS groups regarding age (68.49 vs 66.30 years, $P=0.2273)$, gender $(P=0.4001)$, and BMI (22.21 vs $\left.22.01 \mathrm{~kg} / \mathrm{m}^{2}, P=0.694\right)$. Preoperative physical status was scored using ASA classification, and all the patients were ASA class I, II, or III, with no difference between the groups $(P=0.292)$. To compare the possibility of adhesion during the surgery, surgical history of the abdomen was compared, but no significant differences were found (32.94\% vs $42 \%, P=0.2378$ ); furthermore, there was no difference in the mean size of tumor in the two groups $(35.51$ vs $37.34 \mathrm{~mm}, P=0.5781)$. Various surgical procedures were performed; laparoscopic-assisted ascending colon resection (LACAR) and laparoscopic-assisted Hartmann's operation (LA Hartmann's operation) were only performed in the QS group; however, there was no significant difference between these two surgical procedures $(P=0.830)$. Regarding the method of anastomosis, there was a significant difference ( $P=0.0002)$ between the two groups; functional end-to-end anastomosis (FEEA) was more frequently used in the QS group $(56.47 \%$ vs $36 \%, P=0.0109)$, whereas handsewn anastomosis was more frequently performed in the NQS group $(0.59 \%$ vs $12 \%, P=0.001)$, and Albert-Lembert suture was performed in almost all the handsewn anastomoses. The 1:1 PS-matched cohort comprised 43 patients from the QS group and 43 from the NQS group. The differences in patient characteristics between the QS and NQS groups in the original analysis were alleviated after PSM (Table 2). No significant difference was observed in any item. 
Table 1 Univariate analysis and multivariate analysis of bleeding, operation time, and conversion

\begin{tabular}{|c|c|c|c|c|c|c|c|c|}
\hline Bleeding & Univariate & Multivariate & operation time & Univariate & Multivariate & Conversion & Univariate & Multivariate \\
\hline Age & 0.176 & 0.08474 & & 0.5061 & 0.53396 & & 0.2371 & $0.00001^{*}$ \\
\hline Gender & 0.0602 & 0.13326 & & $0.0204^{*}$ & 0.07094 & & 0.4712 & $0.00001^{*}$ \\
\hline ASA & 0.6456 & 0.82847 & & 0.1773 & 0.1221 & & 0.1401 & $0.00001^{*}$ \\
\hline BMI & 0.2677 & 0.3456 & & 0.0773 & $0.02911^{*}$ & & 0.4072 & 0.99985 \\
\hline Location & 0.9927 & 0.48422 & & $0.0001^{*}$ & $0.02309^{*}$ & & 0.1272 & 0.99512 \\
\hline Operation & 0.1728 & 0.07998 & & $0.0001^{*}$ & $0.00001 *$ & & 0.9072 & $0.00243^{*}$ \\
\hline Anastomosis & 0.809 & 0.27839 & & $0.0001^{*}$ & $0.00283^{*}$ & & 0.0897 & $0.00001^{*}$ \\
\hline History of abdominal surgery & 0.8172 & 0.95322 & & 0.0844 & 0.05482 & & 0.532 & 0.73795 \\
\hline NQS & $0.0488^{*}$ & 0.08287 & & $0.0001^{*}$ & $0.00001^{*}$ & & $0.0005^{*}$ & $0.00001^{*}$ \\
\hline
\end{tabular}

${ }^{*} P<0.05$

\section{Short-term outcome}

Table 3 shows short-term outcomes in the two groups before and after PSM. Compared with the QS group, mean operation time was significantly longer in the NQS group (213.4 min vs $291.7 \mathrm{~min}, P=0.0001,221.6$ min vs $304.6 \mathrm{~min}, P=0.007$ ). Blood loss was minimal in both groups; however, mean bleeding amount was significantly less in the QS group $(25.52 \mathrm{ml}$ vs $45.54 \mathrm{ml}$, $P=0.0488,17.47 \mathrm{ml}$ vs $48.6 \mathrm{ml}, P=0.0436$ ). Lymph node dissection level was no significant differences were observed after PSM $(P=0.3833)$. Regarding the number of harvested lymph nodes, the number of exploited lymph nodes was higher in the QS group (20.19 vs $12.42, P=0.0001,18.74$ vs $12.44, P=0.003)$. Conversion to open surgery occurred in four cases, all in the NQS group ( $0 \%$ vs $8 \%, P=0.0002)$ before PSM. However, after PSM, no significant differences were observed $(0 \%$ vs $6.98 \%, P=0.0779$ ). Regarding complications, no significant difference was observed between the groups (25.29\% vs $28 \%, P=0.7011,27.91 \%$ vs $25.58 \%, P=0.8075$ ); furthermore, the Clavien-Dindo classification showed no difference between the groups. One case in each group required surgery because of a major anastomotic leak. There was no difference between the groups regarding postoperative hospital stay ( 13.15 days vs 13.78 days, $P=0.6057$, 12.56 days vs 13.63 days, $P=0.3618$ ). On multivariate analysis, surgical time in the QS group was detected as a significant factor $(P=0.0001)$, including the gender and surgical method. No significant factor could be detected by multivariate analysis regarding bleeding volume. Regarding the rate of conversion to an open procedure, being in the NQS group became a factor with a significant difference $(P=0.0003)$.

\section{Discussion}

Laparoscopic surgery is being performed worldwide at many facilities. While it has many positive aspects for patients, it is technically challenging for the surgeon and surgical team [1,2]. There is a push to standardize laparoscopic surgery, and ESSQS serves to maintain and improve the quality of surgical technique and the standardization of laparoscopic surgery in Japan [3-5]. This system is unique to Japan and unmatched elsewhere in the world. There are few published articles related to ESSQS, so it is very difficult to find proof of its effectiveness in the literature [6-11]. Through our retrospective single-facility study, we showed the usefulness of ESSQS for the first time.

There were no differences regarding patient background in our study, but there was a difference in the proportion of intestinal anastomosis during surgery. At our facility, the choice of anastomosis during surgery is left to the lead surgeon. There are cases where the intestinal tract length is insufficient and stapled anastomosis is difficult, but there is a possibility that this is determined by a surgeon who is not proficient in handsewn anastomosis. The possibility of difference in the anastomosis method influencing the operation time and bleeding amount in this study cannot be denied. Regarding anastomotic leakage, Choy concluded that stapled anastomosis results in less leakage than handsewn anastomosis [12-17]. In addition, data on short surgical time is recognized [14, 18]. Regarding bleeding, we did not acknowledge the paper which recognizes a big difference in the range to be examined $[15,16]$.

The results of our study show that the surgical time and bleeding amount were significantly lower in the QS group. On comparing with the JCOG 0404 study on bleeding volume and surgery time, the QS group showed nearly comparable results, but the NQS group showed longer operation time and greater bleeding amount [19]. This indicates that ESSQS-QS may be able to control bleeding more accurately, perform the standardized procedure faster, and instruct other physicians in the technique. Regarding operation time, multivariate analysis showed ESSQS qualification to be a risk factor along with gender, tumor site, operation method, and anastomosis method. However, 
Table 2 Patient characteristics before and after PSM

\begin{tabular}{|c|c|c|c|c|c|c|c|}
\hline Before PSM & $\begin{array}{l}\text { QS } \\
n ?=? 170\end{array}$ & $\begin{array}{l}\text { NQS } \\
n ?=? 50\end{array}$ & $p$ value & After PSM & $\begin{array}{l}\text { QS } \\
n ?=? 43\end{array}$ & $\begin{array}{l}\text { NQS } \\
n ?=? 43\end{array}$ & $p$ value \\
\hline Mean age (years) & 68.49 & 66.3 & 0.2273 & & 65.65 & 65.19 & 0.8589 \\
\hline Gender female & $44.71 \%(n ?=? 76)$ & $38 \%(n ?=? 19)$ & 0.4001 & & $39.53 \%(n ?=? 17)$ & $39.53 \%(n ?=? 17)$ & 1 \\
\hline Mean BMI $\left(\mathrm{Kg} / \mathrm{m}^{2}\right)$ & 22.21 & 22.01 & 0.694 & & 21.65 & 22.37 & 0.293 \\
\hline ASA & & & 0.292 & & & & 0.8204 \\
\hline Class 1 & $7.65 \%(n ?=? 13)$ & $14 \%(n ?=? 7)$ & 0.1696 & & $11.63 \%(n ?=? 5)$ & $16.28 \%(n ?=? 7)$ & 0.5337 \\
\hline Class II & $72.35 \%(n ?=? 123)$ & $72 \%(n ?=? 36)$ & 0.9609 & & $76.74 \%(n ?=? 33)$ & $72.09 \%(n ?=? 31)$ & 0.6211 \\
\hline Class III & $20 \%(n ?=? 34)$ & $14 \%(n ?=? 7)$ & 0.3382 & & $11.63 \%(n ?=? 5)$ & $11.63 \%(n ?=? 5)$ & 1 \\
\hline History of abdominal surgery + & $32.94 \%(n ?=? 56)$ & $42 \%(n ?=? 21)$ & 0.2378 & & $32.56 \%(n ?=? 14)$ & $34.88 \%(n ?=? 15)$ & 0.8196 \\
\hline Stage & & & 0.6068 & & & & 0.5808 \\
\hline 0 & $3.53 \%(n ?=? 6)$ & $4 \%(n ?=? 2)$ & 0.8758 & & $4.65 \%(n ?=? 2)$ & $4.65 \%(n ?=? 2)$ & 1 \\
\hline 1 & $28.24(n ?=? 48)$ & $30 \%(n ?=? 15)$ & 0.8083 & & $37.21 \%(n ?=? 16)$ & $25.58 \%(n ?=? 11)$ & 0.2453 \\
\hline$\|$ & $31.18 \%(n ?=? 53)$ & $22 \%(n ?=? 11)$ & 0.2092 & & $18.6 \%(n ?=? 8)$ & $20.93 \%(n ?=? 9)$ & 0.7866 \\
\hline Illa & $16.47 \%(n ?=? 28)$ & $26 \%(n ?=? 13)$ & 0.1282 & & $13.95 \%(n ?=? 6)$ & $27.91 \%(n ?=? 12)$ & 0.1117 \\
\hline Illb & $9.41 \%(n ?=? 16)$ & $6 \%(n ?=? 3)$ & 0.4571 & & $4.65 \%(n ?=? 2)$ & $6.98 \%(n ?=? 3)$ & 0.7142 \\
\hline IV & $11.18 \%(n ?=? 19)$ & $12 \%(n ?=? 6)$ & 0.8719 & & $20.93 \%(n ?=? 9)$ & $13.95 \%(n ?=? 6)$ & 0.3939 \\
\hline Anastomosis & & & $0.0002^{*}$ & & & & 0.7737 \\
\hline FEEA & $56.47 \%(n ?=? 96)$ & $36 \%(n ?=? 18)$ & $0.0109^{*}$ & & 44.19\% (n?=?19) & $41.86 \%(n ?=? 18)$ & 0.8276 \\
\hline DST & $40.59 \%(n ?=? 69)$ & $50 \%(n ?=? 25)$ & 0.237 & & $51.16 \%(n ?=? 22)$ & $55.81 \%(n ?=? 24)$ & 0.6656 \\
\hline handsewn & $0.59 \%(n ?=? 1)$ & $12 \%(n ?=? 1)$ & $0.0001^{*}$ & & $2.33 \%(n ?=? 1)$ & $0 \%(n ?=? 0)$ & 0.3145 \\
\hline none & $2.35 \%(n ?=? 4)$ & $2 \%(n ?=? 1)$ & 0.883 & & $2.33 \%(n ?=? 1)$ & $2.33 \%(n ?=? 1)$ & 1 \\
\hline Tumor size (mm) & 35.51 & 37.34 & 0.5781 & & 36.28 & 36.79 & 0.9043 \\
\hline Location & & & 0.0945 & & & & 0.8245 \\
\hline colon & $77.65 \%(n ?=? 132)$ & $66 \%(n ?=? 33)$ & 0.0945 & & $60.47 \%(n ?=? 26)$ & $62.79 \%(n ?=? 27)$ & 0.8245 \\
\hline rectum & $22.35 \%(n ?=? 38)$ & $34 \%(n ?=? 17)$ & 0.0945 & & $39.53 \%(n ?=? 17)$ & $37.21 \%(n ?=? 16)$ & 0.8245 \\
\hline Operation & & & 0.83 & & & & 0.712 \\
\hline LAAPR & $1.18 \%(n ?=? 2)$ & $2 \%(n ?=? 1)$ & 0.6589 & & $2.33 \%(n ?=? 1)$ & $2.33 \%(n ?=? 1)$ & 1 \\
\hline LAAR & $11.76 \%(n ?=? 20)$ & $18 \%(n ?=? 9)$ & 0.2519 & & $20.93 \%(n ?=? 9)$ & $20.93 \%(n ?=? 9)$ & 1 \\
\hline LACAR & $1.18 \%(n ?=? 2)$ & $0 \%(n ?=? 0)$ & 0.441 & & $2.33 \%(n ?=? 1)$ & $0 \%(n ?=? 0)$ & 0.3145 \\
\hline LACDR & $1.18 \%(n ?=? 2)$ & $2 \%(n ?=? 1)$ & 0.6589 & & $2.33 \%(n ?=? 1)$ & $0 \%(n ?=? 0)$ & 0.3145 \\
\hline LACSR & $22.35 \%(n ?=? 38)$ & $20 \%(n ?=? 10)$ & 0.7233 & & $11.63 \%(n ?=? 5)$ & $16.28 \%(n ?=? 7)$ & 0.5337 \\
\hline LACTR & $7.65 \%(n ?=? 13)$ & $4 \%(n ?=? 2)$ & 0.3685 & & $9.3 \%(n ?=? 4)$ & $2.33 \%(n ?=? 1)$ & 0.1668 \\
\hline LA Hartmann' operation & $1.18 \%(n ?=? 2)$ & $0 \%(n ?=? 0)$ & 0.441 & & $0 \%(n ?=? 0)$ & $0 \%(n ?=? 0)$ & 1 \\
\hline LAICR & $12.35 \%(n ?=? 21)$ & $8 \%(n ?=? 4)$ & 0.3939 & & $11.63 \%(n ?=? 5)$ & $9.3 \%(n ?=? 4)$ & 0.7246 \\
\hline LALAR & $12.94 \%(n ?=? 22)$ & $18 \%(n ?=? 9)$ & 0.3661 & & $23.26 \%(n ?=? 10)$ & $18.6 \%(n ?=? 8)$ & 0.596 \\
\hline LALt.hemi.CR & $6.47 \%(n ?=? 11)$ & $10 \%(n ?=? 5)$ & 0.5936 & & $4.65 \%(n ?=? 2)$ & $9.3 \%(n ?=? 4)$ & 0.3972 \\
\hline LARt.hemi.CR & $21.76 \%(n ?=? 37)$ & $18 \%(n ?=? 9)$ & 0.4571 & & $11.63 \%(n ?=? 5)$ & $20.93 \%(n ?=? 9)$ & 0.2427 \\
\hline
\end{tabular}

regarding the amount of bleeding, ESSQS qualification was not found to be a risk factor in multivariate analysis. Because laparoscopic surgery generally involves a small amount of bleeding, there is a possibility that it is difficult to detect as a significant difference. However, to eliminate these differences, we decided to further modify with PSM and compare the two groups. After PSM, a difference was observed in the amount of bleeding and operation time. However, in our study, it was difficult to compare assistants and cameras separately for surgical assistants. The camera handling by an unexperienced surgeon is one of the major factors in time loosing even when the lead surgeon is experienced in laparoscopic surgery. 
Table 3 Operative and postoperative results before and after PSM

\begin{tabular}{|c|c|c|c|c|c|c|c|}
\hline Before PSM & $\begin{array}{l}\text { QS } \\
n ?=? 170\end{array}$ & $\begin{array}{l}\text { NQS } \\
n ?=? 50\end{array}$ & $p$ value & After PSM & $\begin{array}{l}\text { QS } \\
n ?=? 43\end{array}$ & $\begin{array}{l}\text { NQS } \\
n ?=? 43\end{array}$ & $p$ value \\
\hline Operation time (min) & 213.4 & 291.7 & $0.0001^{*}$ & & 221.6 & 304.6 & $0.0007^{*}$ \\
\hline Blood loss (ml) & 25.52 & 45.54 & $0.0488^{*}$ & & 17.47 & 48.6 & $0.0436^{*}$ \\
\hline Conversion & $0 \%(n ?=? 0)$ & $8 \%(n ?=? 4)$ & $0.0002^{*}$ & & $0 \%(n ?=? 0)$ & $6.98 \%(n ?=? 3)$ & 0.0779 \\
\hline Harvested lymph nodes & 20.19 & 12.42 & $0.0001^{*}$ & & 18.74 & 12.44 & $0.003^{*}$ \\
\hline Complications & $25.29 \%(n ?=? 43)$ & $28 \%(n ?=? 14)$ & 0.7011 & & $27.91 \%(n ?=? 12)$ & $25.58 \%(n ?=? 11)$ & 0.8075 \\
\hline \multicolumn{8}{|l|}{ Clavien-Dindo } \\
\hline । & $15.29 \%(n ?=? 26)$ & $18 \%(n ?=? 9)$ & 0.6456 & & $18.6 \%(n ?=? 8)$ & $16.28 \%(n ?=? 7)$ & 0.7763 \\
\hline$\|$ & $7.65 \%(n ?=? 13)$ & $6 \%(n ?=? 3)$ & 0.6934 & & $4.65 \%(n ?=? 2)$ & $6.98 \%(n ?=? 3)$ & 0.6449 \\
\hline Illa & $1.76 \%(n ?=? 3)$ & $2 \%(n ?=? 1)$ & 0.9128 & & $4.65 \%(n ?=? 2)$ & $2.33 \%(n ?=? 1)$ & 0.5567 \\
\hline Illb & $0.58 \%(n ?=? 1)$ & $2 \%(n ?=? 1)$ & 0.3552 & & $0 \%(n ?=? 0)$ & $0 \%(n ?=? 0)$ & 1 \\
\hline Hospital stay after surgery (day) & 13.15 & 13.78 & 0.6057 & & 12.56 & 13.63 & 0.3618 \\
\hline Lymph node dissection level & & & $0.0008^{*}$ & & & & 0.3833 \\
\hline D0 & $3.53 \%(n ?=? 6)$ & $6 \%(n ?=? 3)$ & 0.4382 & & $2.33 \%(n ?=? 1)$ & $6.98 \%(n ?=? 3)$ & 0.3068 \\
\hline D1 & $2.35 \%(n ?=? 4)$ & $4 \%(n ?=? 2)$ & 0.5296 & & $0 \%(n ?=? 0)$ & $2.33 \%(n ?=? 1)$ & 0.3145 \\
\hline D2 & $10 \%(n ?=? 17)$ & $32 \%(n ?=? 16)$ & $0.0001^{*}$ & & $18.6 \%(n ?=? 8)$ & $25.58 \%(n ?=? 11)$ & 0.4355 \\
\hline D3 & $82.35 \%(n ?=? 143)$ & $58 \%(n ?=? 29)$ & $0.0001^{*}$ & & $79.07 \%(n ?=? 34)$ & $65.12 \%(n ?=? 28)$ & 0.1492 \\
\hline
\end{tabular}

${ }^{*} P<0.05$

Also, the same can be said for the assistant. Of course, it could also cause bleeding.

Conversion to open surgery occurred in four cases in the NQS group because of adhesion. Although it is difficult to evaluate the rate of conversion to an open approach, the results of a multicenter randomized controlled trial showed that conversion to open surgery has increased in laparoscopic colorectal resection cases in patients with physical status ASA III and above, hemiright or left colon resection, sigmoidectomy, low anterior resection, or abdominoperineal resection [19-25]. However, a recent study reported that there was no correlation between ASA and BMI regarding laparotomy conversion rate [26, 27]. Conversely, a study reported that the rate of conversion increased in cases with $\mathrm{BMI} \geq 27.5 \mathrm{~kg} / \mathrm{m}^{2}$, with the rate of conversion being as high as $\geq 20 \%$. It was also noted that many surgeons did not reach the learning curve for ESSQS qualification, so definite prediction it is difficult to judge as a factor [23]. In our study, the lead surgeon determined conversion to an open approach. There is a high possibility that surgery can be completed without laparotomy by more experienced surgeons; however, conversion is by no means a surgical error if it is necessary for patient safety. We believe that safely performing a surgery depends on surgeons' skills as well. However, these results could not be confirmed by the modified PSM comparison because our study changed the number of patients who converted into laparotomy surgery, further accumulation of cases is necessary in the future.
Regarding lymph node dissection and the number of harvested lymph nodes, the QS group was more widely dissected and many lymph nodes could be collected. This results of the extent of dissection are indicated by postoperative pathological results. The extent of lymph node dissection was discussed before surgery, surgery was performed accordingly. However, in this study, the final lymph node dissection extent was defined by the presence of lymph nodes, with or without metastasis. This result also reflects that ESSQS-QS can perform more precise dissections and is also familiar with D3 cases. However, because troubleshooting such as response to bleeding may be more effective with ESSQS$\mathrm{QS}$, dissection can be more precise in the QS group. Also, with more accurate technique, more accurate dissection might have been possible in the QS group. The number of lymph node dissections in our study was not significantly different from those reported in other studies [28]. However, these results also showed no difference after PSM. Considering this, it is highly likely that the number of lymph node dissection levels do not lead to a difference in the two groups. To lead out these conclusions, further accumulation of cases and improvements in study methods are required.

There was no significant difference in postoperative complications and hospital stay between the QS and NQS groups, and in each group, surgery became necessary in only one case due to a major leakage. Both groups show a good postoperative course. Even with the JCOG0404 study, the rate of complications was reasonable [18]. 
Table 4 Patient characteristics in QSA and NQS groups before and after PSM

\begin{tabular}{|c|c|c|c|c|c|c|c|}
\hline Before PSM & $\begin{array}{l}\text { QSA } \\
n=52\end{array}$ & $\begin{array}{l}\text { NQS } \\
n=50\end{array}$ & $p$ value & After PSM & $\begin{array}{l}\text { QSA } \\
n=33\end{array}$ & $\begin{array}{l}\text { NQS } \\
n=33\end{array}$ & $p$ value \\
\hline Mean age (years) & 68.21 & 66.3 & 0.4076 & & 67.76 & 67.24 & 0.8625 \\
\hline Gender Female & $42.31 \%(n=22)$ & $38 \%(n=19)$ & 0.6573 & & $42.42 \%(n=19)$ & $39.39 \%(n=20)$ & 0.8023 \\
\hline Mean BMI $\left(\mathrm{Kg} / \mathrm{m}^{2}\right)$ & 22.1 & 22.01 & 0.8865 & & 22.94 & 22.36 & 0.4978 \\
\hline ASA & & & 0.2356 & & & & 0.8669 \\
\hline Class 1 & $5.77 \%(n=3)$ & $14 \%(n=7)$ & 0.1623 & & $9.09 \%(n=3)$ & $12.12 \%(n=4)$ & 0.6893 \\
\hline Class $\|$ & $71.15 \%(n=37)$ & $72 \%(n=36)$ & 0.9245 & & $78.79 \%(n=26)$ & $78.79 \%(n=26)$ & 1 \\
\hline Class III & $23.08(n=12)$ & $14 \%(n=7)$ & 0.2392 & & $12.12 \%(n=4)$ & $9.09 \%(n=3)$ & 0.6893 \\
\hline History of abdominal surgery + & $34.62 \%(n=18)$ & $42 \%(n=21)$ & 0.443 & & $42.42 \%(n=14)$ & $33.33 \%(n=11)$ & 0.4465 \\
\hline Stage & & & 0.6546 & & & & 0.9823 \\
\hline 0 & $7.69 \%(n=4)$ & $4 \%(n=2)$ & 0.4282 & & $6.06 \%(n=2)$ & $6.06 \%(n=2)$ & 1 \\
\hline । & $34.62 \%(n=18)$ & $30 \%(n=15)$ & 0.6184 & & $27.27 \%(n=9)$ & $30.3 \%(n=10)$ & 0.7857 \\
\hline$\|$ & $25 \%(n=13)$ & $22 \%(n=11)$ & 0.721 & & $27.27 \%(n=9)$ & $21.21 \%(n=7)$ & 0.5657 \\
\hline Illa & $17.31 \%(n=9)$ & $26 \%(n=13)$ & 0.286 & & $24.24 \%(n=8)$ & $21.21 \%(n=7)$ & 0.769 \\
\hline Illb & $9.62 \%(n=5)$ & $6 \%(n=3)$ & 0.561 & & $6.06 \%(n=2)$ & $9.09 \%(n=3)$ & 0.6121 \\
\hline IV & $5.77 \%(n=3)$ & $12 \%(n=6)$ & 0.2674 & & $9.09 \%(n=3)$ & $12.12 \%(n=4)$ & 0.6893 \\
\hline Anastomosis & & & $0.0096^{*}$ & & & & 0.6223 \\
\hline FEEA & $61.54 \%(n=32)$ & $36 \%(n=18)$ & $0.0099^{*}$ & & $51.52 \%(n=17)$ & $45.45 \%(n=15)$ & 0.6223 \\
\hline DST & $38.46 \%(n=20)$ & $50 \%(n=25)$ & 0.2407 & & $48.48 \%(n=16)$ & $54.55 \%(n=18)$ & 0.6223 \\
\hline handsewn & $0 \%(n=0)$ & $12 \%(n=6)$ & $0.01^{*}$ & & $0 \%(n=0)$ & $0 \%(n=0)$ & 1 \\
\hline none & $0 \%(n=0)$ & $2 \%(n=1)$ & 0.3054 & & $0 \%(n=0)$ & $0 \%(n=0)$ & 1 \\
\hline Tumor size (mm) & 32.84 & 37.34 & 0.2478 & & 35.85 & 35.36 & 0.918 \\
\hline Location & & & $0.0289^{*}$ & & & & 0.2689 \\
\hline colon & $84.62 \%(n=44)$ & $66 \%(n=33)$ & $0.0289^{*}$ & & $78.79 \%(n=26)$ & $66.67 \%(n=22)$ & 0.2689 \\
\hline rectum & $15.38 \%(n=8)$ & $34 \%(n=17)$ & $0.0289^{*}$ & & $21.21 \%(n=7)$ & $33.33 \%(n=11)$ & 0.2689 \\
\hline Operation & & & 0.1473 & & & & 0.8838 \\
\hline LAAPR & $0 \%(n=0)$ & $2 \%(n=1)$ & 0.3054 & & $0 \%(n=0)$ & $0 \%(n=0)$ & 1 \\
\hline LAAR & $15.38 \%(n=8)$ & $18 \%(n=9)$ & 0.7231 & & $18.18 \%(n=6)$ & $24.24 \%(n=8)$ & 0.547 \\
\hline LACAR & $0 \%(n=0)$ & $0 \%(n=0)$ & 1 & & $0 \%(n=0)$ & $0 \%(n=0)$ & 1 \\
\hline LACDR & $0 \%(n=0)$ & $2 \%(n=1)$ & 0.3054 & & $0 \%(n=0)$ & $0 \%(n=0)$ & 1 \\
\hline LACSR & $26.92 \%(n=14)$ & $20 \%(n=10)$ & 0.4099 & & $24.24 \%(n=8)$ & $18.18 \%(n=6)$ & 0.547 \\
\hline LACTR & $3.85 \%(n=2)$ & $4 \%(n=2)$ & 0.9681 & & $3.3 \%(n=1)$ & $3.3 \%(n=1)$ & 1 \\
\hline LA Hartmann operation & $0 \%(n=0)$ & $0 \%(n=0)$ & 1 & & $0 \%(n=0)$ & $0 \%(n=0)$ & 1 \\
\hline LAICR & $19.23 \%(n=10)$ & $8 \%(n=4)$ & 0.0994 & & $15.15 \%(n=5)$ & $12.12 \%(n=4)$ & 0.7198 \\
\hline LALAR & $3.85 \%(n=2)$ & $18 \%(n=9)$ & $0.0212^{*}$ & & $6.06 \%(n=2)$ & $15.15 \%(n=5)$ & 0.2304 \\
\hline LALt.hemi.CR & $3.85 \%(n=2)$ & $10 \%(n=5)$ & 0.2191 & & $6.06 \%(n=2)$ & $3.3 \%(n=1)$ & 0.5546 \\
\hline LARt.hemi.CR & $26.92 \%(n=14)$ & $18 \%(n=9)$ & 0.281 & & $27.27 \%(n=9)$ & $24.24 \%(n=8)$ & 0.7783 \\
\hline
\end{tabular}

There was no difference between the groups regarding postoperative hospital days. As postoperative management of patients at our facility is performed by a team, there was little difference between the groups regarding the timing of discharge and judgment of complications. Also, postoperative management is unified. Thus, there is a possibility that this result may have strong evidence.
Based on the abovementioned results, the ESSQS certification process for colorectal surgical technique is accurately performed by the association. In a study similar to ours, Nijhof et al. compared experts and residents for laparoscopic colorectal surgical skills and obtained results different from ours. This may indicate the difference between an expert surgeon and ESSQS- QS [29]. 
Table 5 Operative and postoperative results in QSA and NQS groups before and after PSM

\begin{tabular}{|c|c|c|c|c|c|c|c|}
\hline Before PSM & $\begin{array}{l}\text { QSA } \\
n=52\end{array}$ & $\begin{array}{l}\text { NQS } \\
n=50\end{array}$ & $p$ value & After PSM & $\begin{array}{l}\text { QSA } \\
n=33\end{array}$ & $\begin{array}{l}\text { NQS } \\
n=33\end{array}$ & $p$ value \\
\hline Operation time (min) & 217.48 & 291.7 & $0.0002^{*}$ & & 224.3 & 272.24 & $0.0481^{*}$ \\
\hline Blood loss (ml) & 22.9 & 45.54 & 0.0934 & & 26.55 & 40.3 & 0.3838 \\
\hline Conversion & $0 \%(n=0)$ & $8 \%(n=4)$ & $0.0194^{*}$ & & $0 \%(n=0)$ & $9.09 \%(n=3)$ & 0.0763 \\
\hline Harvested lymph nodes & 20.48 & 12.42 & $0.0004^{*}$ & & 19.97 & 13.15 & $0.0163^{*}$ \\
\hline Complications & $19.23 \%(n=10)$ & $28 \%(n=14)$ & 0.2966 & & $24.24 \%(n=8)$ & $24.24 \%(n=8)$ & 1 \\
\hline \multicolumn{8}{|l|}{ Clavien-Dindo } \\
\hline । & $7.69 \%(n=4)$ & $18 \%(n=9)$ & 0.1186 & & $12.12 \%(n=4)$ & $18.18 \%(n=6)$ & 0.4923 \\
\hline$\|$ & $7.69 \%(n=4)$ & $6 \%(n=3)$ & 0.7354 & & $6.06 \%(n=2)$ & $3.03 \%(n=1)$ & 0.5546 \\
\hline Illa & $1.92 \%(n=1)$ & $2 \%(n=1)$ & 0.9777 & & $3.03 \%(n=1)$ & $3.03 \%(n=1)$ & 1 \\
\hline$\| l l b$ & $1.92 \%(n=1)$ & $2 \%(n=1)$ & 0.9777 & & $3.03 \%(n=1)$ & $0 \%(n=0)$ & 0.3136 \\
\hline Hospital stay after surgery (day) & 12.98 & 13.78 & 0.1967 & & 12.7 & 13.55 & 0.63 \\
\hline Lymph node dissection level & & & $0.0439^{*}$ & & & & 0.267 \\
\hline D0 & $5.77 \%(n=3)$ & $6 \%(n=3)$ & 0.9605 & & $3.03 \%(n=1)$ & $6.06 \%(n=2)$ & 0.5546 \\
\hline D1 & $3.85 \%(n=2)$ & $4 \%(n=2)$ & 0.9681 & & $3.03 \%(n=1)$ & $3.03 \%(n=1)$ & 1 \\
\hline D2 & $9.62 \%(n=5)$ & $32 \%(n=16)$ & $0.0052^{*}$ & & $12.12 \%(n=4)$ & $30.3 \%(n=10)$ & 0.0708 \\
\hline D3 & $80.77 \%(n=42)$ & $58 \%(n=29)$ & $0.0124^{*}$ & & $81.82 \%(n=27)$ & $60.61 \%(n=20)$ & 0.057 \\
\hline
\end{tabular}

${ }^{*} P<0.05$

On the other hand, another evaluation of technique for certification is a surgeon meeting the predetermined criteria as evaluated by another, more experienced surgeon. Also, in this study, we compared, as a subsidiary, a group of interventions between ESSQS-QS who assisted the non-ESSQS-QS and non-ESSQS-QS. As seen in Tables 4 and 5, before PSM surgery time, laparotomy conversion rate, and lymph node dissection showed significantly better results for the interventions by ESSQS- QS. Also, after PSM showed significantly better results in operation time and harvested lymph nodes. This result is similar to those reported in the literature and is one of the indicators of the quality of technical certification [30].

This research has some limitations. We modified using PSM and compared to enhance the research; however, there are still some limitations. It is a retrospective study, and there are certain differences in the patient background. Furthermore, there are more cases in the QS group than in the NQS group, which may result in a difference in results. Moreover, it is thought that there is a difference in the skill level of the caster. ESSQS-QS has considerable laparoscopic surgery experience. However, surgeons performing the procedure in the NQS group may have little experience in laparoscopic surgery. This seems to be a strong factor in the results of our study. Also, our study includes data only from a single facility, and the number of cases is small. A multicenter study with a large sample size is needed to comprehensively evaluate this issue in the future.

\section{Conclusion}

Our results indicate that a laparoscopic colorectal surgery performed by ESSQS-QS leads to good short-term outcomes. ESSQS is potentially useful in maintaining and improving the quality of surgical techniques and in standardization of laparoscopic surgery in Japan.

\section{Abbreviations}

ASA: American Society of Anesthesiologists; BMl: Body mass index; DST: Double stapling technique; ESSQS: Endoscopic Surgical Skill

Qualification System; FEEA: Functional end-to-end anastomosis; JSES: Japan Society for Endoscopic Surgery; LA Hartmann's operation: Laparoscopyassisted Hartmann's operation; LAAPR: Laparoscopy-assisted abdominoperineal resection; LAAR: Laparoscopy-assisted anterior resection; LACAR: Laparoscopy-assisted ascending colon resection; LACDR: Laparoscopy-assisted descending colon resection;

LACSR: Laparoscopy-assisted sigmoid colon resection; LACTR: Laparoscopyassisted transverse colon resection; LALAR: Laparoscopy-assisted low anterior resection; LALt.hemi.CR: Laparoscopy-assisted left hemicolectomy;

LARt.hemi.CR: Laparoscopy-assisted right hemicolectomy; PSM: Propensity score matching; QS: Qualified surgeon; QSA: Qualified surgeon assist

\section{Acknowledgments}

The authors are grateful to all the patients who contributed data to this study. We would like to thank R. Nakagawa for useful discussions and Y. Sato for assistance with statistical processing. The authors would like to thank Enago (http://www.enago.com) for the English language review.

\section{Authors' contributions}

SA operated surgery and performed postoperative management of the patient and wrote the manuscript. SA and TO gathered and analyzed the data, participated in an extensive literature review. $\mathrm{Yl}, \mathrm{TO}$ and $\mathrm{Ml}$ are the senior surgeon, who operated on the patient, and gave advice on surgery and postoperative management. MY supervised and contributed to the final version of the report. All authors read and approved the final manuscript. 


\section{Funding}

This research did not receive any specific grant funding from agencies in the public, commercial, or not-for-profit sectors.

\section{Availability of data and materials}

All of the data are available without restriction. The data are available from the corresponding author upon reasonable request.

\section{Ethics approval and consent to participate}

This study obtained ethical approval from the institutional review board of the Tokyo Women's Medical University Hospital (IRB\#4766). Written informed consent was provided by the patients for their information and specimens to be stored in the hospital database and used in research.

\section{Consent for publication}

This study was granted of consent and permission for publication from the Tokyo Women's Medical University Hospital (IRB\#4766). Written consent was given by patients to use their information in a research study and publish it.

\section{Competing interests}

Dr. Shota Aoyama, Yuji Inoue, Takeshi Ohki, Michio Itabashi, and Masakazu Yamamoto have no conflicts of interest to disclose.

\section{Received: 22 June 2018 Accepted: 4 June 2019}

\section{Published online: 11 July 2019}

\section{References}

1. Clinical Outcomes of Surgical Therapy Study Group. A comparison of laparoscopically assisted and open colectomy for colon cancer. N Engl J Med. 2004;350:2050-9.

2. Guillou PJ, Quirke P, Thorpe H, Walker J, Jayne DG, Smith AM, Heath RM, Brown JM, MRC CLASICC trial group. Short- term endpoints of conventional versus laparoscopic-assisted surgery in patients with colorectal cancer (MRC CLASICC trial): multicentre, randomised controlled trial. Lancet. 2005;365: 1718-26.

3. Kimura T, Mori T, Konishi F, Kitajima M. Endoscopic surgical skill qualification system in Japan: five years of experience in the gastrointestinal field. Asian J Endosc Surg. 2010;3:66-70.

4. Yamakawa T, Kimura T, Matsuda T, Konishi F, Bandai Y. Endoscopic surgical skill qualification system (ESSQS) of the Japanese Society of Endoscopic Surgery (JSES). BH Surg. 2013;3:6-8.

5. Mori T, Kimura T, Kitajima M. Skill accreditation system for laparoscopic gastroenterologic surgeons in Japan. Minim Invasive Ther Allied Technol. 2010;19:18-23.

6. Habuchi T, Terachi T, Mimata H. Evaluation of 2,590 urological laparoscopic surgeries undertaken by urological surgeons accredited by an endoscopic surgical skill qualification system in urological laparoscopy in Japan. Surg Endosc. 2012;26:1656-63.

7. Tanigawa N, Lee SW, Kimura T, Mori T, Uyama I, Nomura E, Okuda J, Konishi F. The endoscopic surgical skill qualification system for gastric surgery in Japan. Asian J Endosco Surg. 2011;4:112-5.

8. Iwanaka T, Morikawa Y, Yamataka A, Nio M, Segawa O, Kawashima H, Sato M, Terakura $H$, Take $H$, Hirose $R$, Yag M. Skill qualifications in pediatric minimally invasive surgery. Pediatr Surg Int. 2011;27:727-31.

9. Iwanaka T. Technical innovation, standardization, and skill qualification for pediatric minimally invasive surgery in Japan. J Pediatr Surg. 2009;44:36-42.

10. Matsuda T, Ono Y, Terachi T, Naito S, Baba S, Miki T, Hirao Y, Okuyama A. The endoscopic surgical skill qualification system in urological laparoscopy: a novel system in Japan. J Urol. 2006:176:2168-72.

11. Dindo D, Demartines N, Clavien PA. Classification of surgical complications: a new proposal with evaluation in a cohort of 6336 patients and results of a survey. Ann Surg. 2004;240:205-13.

12. Choy PY, Bissett IP, Docherty JG, Parry BR, Merrie A, Fitzgerald A (2011) Stapled versus handsewn methods for ileocolic anastomoses. Cochrane Database Syst Rev, DOl: https://doi.org/10.1002/14651858.CD004320.pub3, Sep 7, 2011.

13. Didolkar MS, Reed WP, Elias EG, Schnaper LA, Brown SD, Chaudhary SM. A prospective randomized study of sutured versus stapled bowel anastomoses in patients with cancer. Cancer. 1986;57:456-60.

14. Docherty JG, McGregor JR, Akyol AM, Murray GD, Galloway DJ. West of Scotland and Highland anastomosis study group. Comparison of manually constructed and stapled anastomoses in colorectal surgery. Ann Surg. 1995; 221:176-84.

15. Ikeuchi H, Kusunoki M, Yamamura T. Long-term results of stapled and handsewn anastomoses in patients with Crohn's disease. Digest Surg. 2000; 17:493-6.

16. Izbicki JR, Gawad KA, Quirrenbach S, Hosch SB, Breid V, Knoefel WT. Can stapled anastomosis in visceral surgery still be justified? A prospective controlled randomized study of the cost-effectiveness of handsewn and stapled anastomoses. Chirurg. 1998;69:725-34.

17. Kracht M, Hay JM, Fagniez PL, Fingerhut A. lleocolonic anastomosis after right hemicolectomy for carcinoma: stapled or hand-sewn? Int J Color Dis. 1993:8:29-33.

18. Yamamoto $\mathrm{S}$, Inomata $\mathrm{M}$, Katayama H, Mizusawa J, Etoh $\mathrm{T}$, Konishi $\mathrm{F}$, Sugihara K, Watanabe M, Moriya Y, Kitano S, Japan Clinical Oncology Group Colorectal Cancer Study Group. Short-term surgical outcomes from a randomized controlled trial to evaluate laparoscopic and open D3 dissection for stage II/III colon cancer: Japan clinical oncology group study JCOG 0404. Ann Surg. 2014;260:23-30.

19. Chan AC, Poon JT, Fan JK, Lo SH, Law WL. Impact of conversion on the long-term outcome in laparoscopic resection of colorectal cancer. Surg Endosc. 2008;22:2625-30.

20. Schwandner $\mathrm{O}$, Schiedeck TH, Bruch $\mathrm{H}$. The role of conversion in laparoscopic colorectal surgery: do predictive factors exist? Surg Endosc. 1999:13:151-6.

21. Tan PY, Stephens JH, Rieger NA, Hewett PJ. Laparoscopically assisted colectomy: a study of risk factors and predictors of open conversion. Surg Endosc. 2008:22:1708-14.

22. Buchanan GN, Cohen CR, Nicholls RJ. Randomized clinical trial of the costs of open and laparoscopic surgery for colonic cancer. Br J Surg. 2004;91:1202.

23. Franko J, O'Connell BG, Mehall JR, Harper SJ, Nejman JH, Zebley DM, Fassler SA. The influence of prior abdominal operations on conversion and complication rates in laparoscopic colorectal surgery. JSLS. 2006:169-75.

24. Vignali A, Di Palo S, De Nardi P, Radaelli G, Orsenigo E, Staudacher C. Impact of previous abdominal surgery on the outcome of laparoscopic colectomy: a case-matched control study. Tech Coloproctol. 2007:11:241-6.

25. González Al, Malagón MA, López-Tomassetti Fernández EM, Durán AJ, Luis $\mathrm{DH}$, Pallares CA. Impact of previous abdominal surgery on colorectal laparoscopy results: a comparative clinical study. Surg Laparosc Endosc Perctan Tech. 2006;16:8-11.

26. Yamamoto M, Okuda J, Tanaka K, Kondo K, Asai K, Kayano H, Masubuchi S, Uchiyama K. Effect of previous abdominal surgery on outcomes following laparoscopic colorectal surgery. Dis Colon Rectum. 2013;56:336-42.

27. Marcela R, Martínek L. Conversion risk factors in laparoscopic colorectal surgery. Videosurgery Miniinv. 2012;7:240-5. https://doi.org/10.5114/wiitm. 2011.28906

28. Garcia B, Guzman C, Johnson C, Hellenthal NJ, Monie D, Monzon JR. Trends in lymph node excision and impact of positive lymph node ratio in patients with colectomy for primary colon adenocarcinoma: population based study 1988 to 2011. Surg Oncol. 2016;25:158-63.

29. Nijhof HW, Silvis R, Vuylsteke RC, Oosterling SJ, Rijna H, Stockmann HB. Training residents in laparoscopic colorectal surgery: is supervised surgery safe? Surg Endosc. 2016;31:2602-6.

30. Nobuki I, Shigenori H, Tadashi Y, Yosuke O. Supervision by a technically qualified surgeon affects the proficiency and safety of laparoscopic colectomy performed by novice surgeons. Surg Endosc. 2017:32:436-42.

\section{Publisher's Note}

Springer Nature remains neutral with regard to jurisdictional claims in published maps and institutional affiliations. 